\title{
CXCR2 Blockade Reduces Radical Formation in Hyperoxia-Exposed Newborn Rat Lung
}

\author{
LINGJIE LIAO, QIN NING, YUXIANG LI, WEI WANG, ANRU WANG, WEI WEI, XIN LIU, RICHARD L. AUTEN, \\ A. KEITH TANSWELL, AND XIAOPING LUO
}

\begin{abstract}
Departments of Pediatrics [L.L., Y.L., W.Wa., A.W., W.We., X.Li., X.Lu] and Infectious Diseases [Q.N.], Tongji Hospital, Tongji Medical College, Huazhong University of Science and Technology, Wuhan, Hubei, China, 430030; Department of Pediatrics [R.L.A.] Division of Neonatal Medicine, Duke University Medical Center, Durham, NC 22710; Departments of Paediatrics [A.K.T.] and Physiology [A.K.T.], Hospital for Sick Children, University of Toronto, Toronto, Ontario M5G 1X8, Canada
\end{abstract}

\begin{abstract}
Inflammation contributes greatly to the pathogenesis of bronchopulmonary dysplasia. In previous studies, we showed that blocking neutrophil influx by treatment with SB265610, a selective CXCR2 antagonist, could partly reduce superoxide accumulation and preserve alveolar development in $60 \% \mathrm{O}_{2}$-exposed newborn rats. The purpose of this study was to further investigate the role of neutrophils in the formation of reactive oxygen and nitrogen species mediating hyperoxia-impaired lung development. We found that hydroxyl radical formation and lipid peroxidation in rat lungs were significantly increased during $60 \% \mathrm{O}_{2}$ exposure. These increases were attenuated by the administration of SB265610. In addition, SB265610 largely inhibited protein nitration induced by hyperoxia. SB265610 partly prevented the hyperoxia-enhanced bronchoalveolar lavage (BAL) protein content in $60 \% \mathrm{O}_{2}$-exposed animals. Our results demonstrate that neutrophils have a pivotal role in hydroxyl radical formation, lipid peroxidation and protein nitration. Taken together with our previous studies, the present findings show that blocking neutrophil influx protects alveolar development and improves lung function in part by preventing reactive oxygen/nitrogen species accumulation. (Pediatr Res 60: 299-303, 2006)
\end{abstract}

$\mathrm{I}^{\mathrm{n}}$ nflammation is a common mechanism uniting factors linked to the development of bronchopulmonary dysplasia (BPD), such as oxidative stress, mechanical injury, and defective antioxidant defenses (1). Premature newborns born to mothers with chorioamnionitis are at high risk of developing BPD (2). Likewise, premature newborns with respiratory distress syndrome (RDS) with elevated neutrophil counts in tracheal aspirates at birth are at high risk of developing BPD (3). In the baboon model of BPD, neutrophil chemokine IL-8 is elevated in tracheal aspirates a few days after delivery (4).

While there are no published studies that directly and specifically antagonize neutrophil influx in premature newborn babies, a number of experimental models show beneficial

Received January 11, 2006; accepted May 10, 2006.

Correspondence: Xiaoping Luo, M.D., Department of Pediatrics, Tongji Hospital, 1095 Jie Fang Avenue, Wuhan 430030, China; e-mail: xpluo@tjh.tjmu.edu.cn

This study was supported by the National Natural Science Foundation of China (NSFC) (No.30271379, XL), NSFC National Science Fund for Distinguished Young Investigator (No.30125019, XL; No.30225040, QN), and National Basic Research Program (973 Project 2005CB522507, XL), and National Institutes of Health HL-067021 (RLA). Dr. Tanswell holds the Hospital for Sick Children Women's Auxiliary Chair in Neonatal Medicine.

DOI: $10.1203 / 01 . p d r .0000233058 .08200 . d 6$ effects. Depletion of circulating neutrophils in preterm lambs lessened the severity of pulmonary leak of protein and fluid in experimental RDS (5). Blocking hyperoxia-induced pulmonary neutrophil influx in newborn rats by treatment with neutralizing antibodies to neutrophil chemokines (6) prevented impaired lung compliance (7), DNA oxidation (8), and protected alveolar development $(7)$ in $95 \% \mathrm{O}_{2}$-exposed newborn rats.

To determine the mechanisms by which blocking neutrophil influx could protect lung development, we exposed newborn rat pups to air or $\mathrm{FiO}_{2}=0.6$ for two weeks and treated them with SB-265610, a small molecule selective antagonist of C-X-C chemokine receptor-2 (CXCR2), a dominant neutrophil chemokine receptor. In our previous studies, SB265610 prevented neutrophil accumulation, partly reduced tissue superoxide accumulation, and accelerated alveolar development (9). To determine whether blocking neutrophil influx through this approach could reduce pulmonary hydroxyl radical accumulation, lipid peroxidation, and protein nitration, we performed similar hyperoxia exposures \pm treatment with the CXCR2 antagonist SB265610 and measured hydroxyl radical reaction products, free and esterified 8-isoprostane, and 3-nitrotyrosine. We found that hyperoxia increased bronchoalveolar lavage protein, lung tissue hydroxyl radical, 8-isoprostane and 3-nitrotyrosine accumulation, and that treatment with SB265610 substantially prevented each of these adverse effects.

\section{METHODS}

Materials. SB265610 was kindly provided by Dr. Skip Sarau (Glaxo SmithKline, King of Prussia, PA). A rabbit polyclonal antibody to myeloperoxidase (MPO, for neutrophil identification) was from NeoMarker (Fremont, $\mathrm{CA}$ ). Proliferating cell nuclear antigen (PCNA) MAb was purchased from BD Transduction Laboratories (San Diego, CA). Rabbit polyclonal antibody to

Abbreviations: BAL, bronchoalveolar lavage; BPD, bronchopulmonary dysphasia; CXCR2, C-X-C chemokine receptor-2; 2,3-DHBA, 2,3-dihydroxybenzoic acid; 2,5-DHBA, 2,5-dihydroxybenzoic acid; MPO, myeloperoxidase; WBC, white blood cell; WW/DW, lung wet-to-dry weight ratio 
nitrotyrosine was obtained from Upstate Biotechnology (Lake Placid, NY). Biotinylated goat anti-rabbit IgG, biotinylated goat anti-mouse IgG, biotinylated rabbit anti-goat $\mathrm{IgG}$ 'streptavdin-peroxidase and 3,3'-diaminobenzidine were from Dako (Carpinteria, CA). 8-isoprostane enzyme immunoassay kits were from Cayman Chemical Co. (Ann Arbor, MI). All organic solvents were of HPLC grade. A total protein assay kit was purchased from Bio-Rad (Hercules, CA). Sep Pak C18 cartridges were from Waters (Mississauga, Canada).

Institutional review. All procedures involving animals were conducted according to criteria established by the Chinese Council for Animal Care. Approval for the study was obtained from the Animal Care Review Committee of Tongji Hospital, Tongji Medical College, Huazhong University of Science and Technology.

Exposure system. The exposure system has been described in detail previously (10). Briefly, pathogen-free, timed-pregnant Sprague Dawley rats were obtained from the animal center of Tongji Medical College. Experiments were conducted as paired exposures, with one chamber receiving $60 \% \mathrm{O}_{2}$ and the other receiving air. On the anticipated day of delivery, each dam was placed in a $50 \times 35 \times 40$-cm plastic chamber with $12 \mathrm{~h} / 12 \mathrm{~h}$ light/dark cycles, and a temperature of $25^{\circ} \mathrm{C}$. Food and water were given ad libitum. Dams were exchanged daily between paired chambers to prevent maternal $\mathrm{O}_{2}$ toxicity.

Intervention. Rat pups were maintained in paired chambers (air and $\mathrm{O}_{2}$ ) for the 14-d exposures. Each paired litter received either 0.1\% DMSO in saline (vehicle control) or SB265610 in $0.1 \%$ DMSO in saline $(4 \mu \mathrm{g} / \mathrm{g}$ and 4 $\mu \mathrm{L} / \mathrm{g}$ ) daily s.c. on day $3-10$.

Bronchoalveolar lavage (BAL) cell counting and protein concentration. After $60 \% \mathrm{O}_{2}$ exposure for 7 and $14 \mathrm{~d}$, pups were anesthetized with 150 $\mathrm{mg} / \mathrm{kg}$ sodium pentobarbital IP. Both lungs were slowly lavaged five times via a tracheal cannula with $0.5 \mathrm{~mL} 0.9 \% \mathrm{NaCl}$ containing $1 \mathrm{mM}$ EDTA. Lavage volumes were recorded, and cell counts measured with a hemocytometer. Differential counts of $\geq 200$ cells were obtained using Wright-Giemsa stain. Protein concentration was measured by the method of Bradford (11).

Lung wet-to-dry weight ratio $(W W / D W)$. The unlavaged lungs were removed after sacrifice and the wet weight was measured. The lungs were then placed in pre-weighed tubes and dried to a stable weight at $60^{\circ} \mathrm{C}$ over $48 \mathrm{~h}$.

Sample collection. Animals were anesthetized with $150 \mathrm{mg} / \mathrm{kg}$ sodium pentobarbital IP. While the heart was beating, the pulmonary circulation was flushed with PBS containing $1 \mathrm{U} / \mathrm{mL}$ heparin to clear the lungs of blood, and perfusion fixed with $4 \%$ (wt/vol) paraformaldehyde with a constant airway pressure of $10 \mathrm{~cm} \mathrm{H}_{2} \mathrm{O}$, which was maintained via a tracheal catheter.

Immunohistochemistry. Lung right middle lobes were embedded in paraffin and cut in 5- $\mu \mathrm{m}$ sections. Sections were immunostained using the strepavidin-biotin technique. For neutrophil identification, dilutions of rabbit anti-MPO and biotinylated goat anti-rabbit $\operatorname{IgG}$ were $1: 200$ and 1:250, respectively. For the detection of 3-nitrotyrosine, the dilutions of rabbit anti-nitrotyrosine and biotinylated goat anti-rabbit $\operatorname{IgG}$ were 1:100 and 1:200, respectively. For all antibodies, antibody specificity was verified by replacing the primary antibody with rabbit IgG. Slides were counterstained with Carazzi hematoxylin, dehydrated, cleared in xylene, and mounted.

Hydroxyl radical measurement. The pups were injected with $100 \mathrm{mg} / \mathrm{kg}$ of sodium salicylate IP in $0.9 \% \mathrm{NaCl} 1 \mathrm{~h}$ before euthanasia. Hydroxyl radical formation was assessed by an aromatic hydroxylation assay using gas chromatography/mass spectrometry (GC/MS) with salicylate as the probe. Hydroxyl radical reactions with salicylate produce characteristic decarboxylation and hydroxylation products, 2,3-dihydroxybenzoic acid (2,3-DHBA) and 2,5-dihydroxybenzoic acid (2,5-DHBA). As previously described (12), lungs were homogenized in PBS with EDTA $(400 \mu \mathrm{M})$, butylated hydroxytoluene $(20 \mu \mathrm{M})$, and deferoxamine $(20 \mu \mathrm{M})$ to prevent auto-peroxidation during sample preparation.

Total lung 8-isoprostane (free and esterified) measurement. To prevent auto-oxidation, lung tissue was immediately flash frozen in liquid $\mathrm{N}_{2}$ at harvest and stored at $-80^{\circ} \mathrm{C}$ until analysis. As previous described (13), upon thawing, the tissue sample was homogenized in PBS with $0.005 \%$ (vol/vol) butylated hydroxytoluene, and $100 \mathrm{ng}$ isoprostane was added to quantify recovery during purification. Proteins were precipitated with ethanol and removed by centrifugation. The supernatant was incubated with an equal volume of $15 \%(\mathrm{wt} / \mathrm{vol})$ potassium hydroxide at $40^{\circ} \mathrm{C}$ for $1 \mathrm{~h}$ for alkaline hydrolysis before solid-phase extraction using Sep Pak C18 cartridges. After purification, samples were analyzed in duplicate for 8-isoprostane content using a commercially available ELISA kit.

Statistical analysis. All data except survival rate are presented as mean \pm SEM of five litters. Differences for survival rates between the groups were compared using Fisher's exact test. Differences for other data were evaluated with the SPSS 12.0 package (SPSS, Chicago, IL) using one-way analysis of variance (ANOVA), followed by assessment of differences using StudentNewman-Keuls test. Statistical significance was defined as a $p$ value $<0.05$.

\section{RESULTS}

Effects of the CXCR2 antagonist SB265610 on survival rate and lung injuries after $14 \mathrm{~d}$ exposure to air or $60 \% \mathrm{O}_{2}$ are shown in Table 1. Survival rate and body weight were recorded at the end of the 14-d exposure. There were no significant differences in either survival rate or body weight between groups. However, the survival rate decreased in $60 \%$ $\mathrm{O}_{2}$-exposed animals with or without SB265610 treatment, compared with air-exposed animals. Lung injury was assessed by lung WW/DW ratio and protein concentration in BAL fluid. Compared with air-exposed animals with or without SB265610 injection, WW/DW ratio was significantly increased after $14 \mathrm{~d}$ exposure to $60 \% \mathrm{O}_{2}$, and there was no significant difference between the two hyperoxia-exposed groups. The content of protein in BAL fluid was significantly increased after both 7- and 14-d exposure to $60 \% \mathrm{O}_{2}$, which was partially prevented by SB265610 treatment.

Total white blood cell (WBC) counts and neutrophils in BAL fluid were significantly elevated in pups after both 7- and 14-d exposures to $60 \% \mathrm{O}_{2}$, as compared with air-exposed animals. In the SB265610-treated group, the increases in total WBC were significantly reduced, and elevated neutrophil count was completely attenuated (Fig. 1). MPO immunohistochemistry showed an increased abundance of neutrophils on exposure to $60 \% \mathrm{O}_{2}$ for 7 and $14 \mathrm{~d}$, which was reduced by treatment with SB265610(data not shown), parallel to the

Table 1. The effect of SB265610 on survival rate, lung wet/dry weight ratio and protein concentration in BAL after a 14-day exposure

\begin{tabular}{|c|c|c|c|c|c|}
\hline \multirow[b]{2}{*}{ Group } & \multirow{2}{*}{$\begin{array}{c}\text { Survival rate \% } \\
\text { (survival/total) }\end{array}$} & \multirow[b]{2}{*}{ Body weight (g) } & \multirow{2}{*}{$\begin{array}{l}\text { Lung wet/dry } \\
\text { weight ratio }\end{array}$} & \multicolumn{2}{|c|}{ Protein concentration in BAL $(\mathrm{g} / \mathrm{ml})$} \\
\hline & & & & $7 d$ & $14 \mathrm{~d}$ \\
\hline \multicolumn{6}{|l|}{ Air } \\
\hline SB265610 & $100(53 / 53)$ & $26.69 \pm 0.58$ & $5.09 \pm 0.06$ & $12.30 \pm 0.56$ & $20.54 \pm 1.14$ \\
\hline \multicolumn{6}{|l|}{$60 \% \mathrm{O}_{2}$} \\
\hline Vehicle & $90.9(50 / 55)$ & $25.09 \pm 0.25$ & $6.72 \pm 0.29 *$ & $123.41 \pm 5.87^{*}$ & $168.94 \pm 9.41^{*}$ \\
\hline
\end{tabular}

Results except survival rate are presented as means \pm SEM. Numbers in brackets under survival rate are the sample sizes of survived and total pups in each group.

$* p<0.01$, by one-way ANOVA for animals exposed to $60 \% \mathrm{O}_{2}$ compared with those in air in the same treatment group.

$\dagger p<0.01$, by one-way ANOVA for SB265610-treated animals compared with control animals exposed to the same gas. 

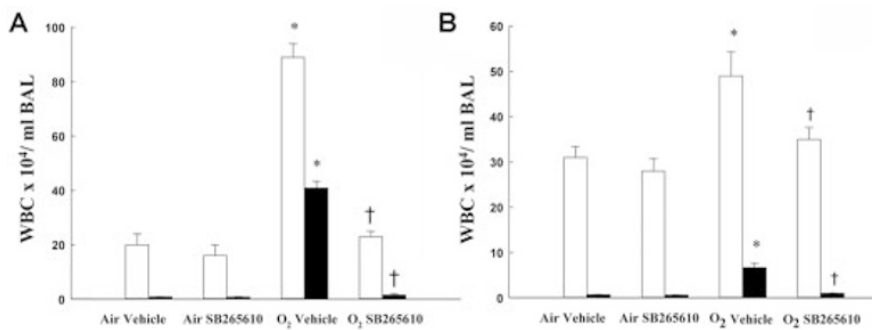

Figure 1. Total WBC $(\square)$ and neutrophil ( $\square)$ counts in BAL of neonatal rats exposed to air or $60 \% \mathrm{O}_{2}+\mathrm{SB} 265610$ or vehicle (A, day $7 ; B$, day 14). Bars represent mean \pm SEM, $n=5 . * p<0.01$, by one-way analysis of variance, for animals exposed to $60 \% \mathrm{O}_{2}$ compared with those in air in the same treatment group. ${ }^{\dagger} p<0.01$, by one-way analysis of variance, for SB265610treated animals compared with control animals exposed to the same gas.

effects on BAL neutrophils. These results were consistent with our previous findings with MPO immunostaining and activity measurements, showing that SB265610 treatment via s.c. as well as IP injection can effectively block $\mathrm{O}_{2}$-dependant pulmonary neutrophil influx in neonatal rats.

Hydroxyl radical formation in rat lungs, as measured by the salicylate hydroxylation products 2,3-DHBA and 2,5-DHBA, was significantly increased after both 7 and $14 \mathrm{~d}$ of exposure to $60 \% \mathrm{O}_{2}$, and this was significantly prevented by the administration of SB265610 (Fig. 2).

As shown in Fig. 3, lung 8-isoprostane content was markedly increased in $60 \% \mathrm{O}_{2}$-exposed rats, as compared with airand vehicle-exposed animals. SB265610 treatment partly reduced the increase in 8-isoprostane content in the lungs of neonatal rats after exposure to $60 \% \mathrm{O}_{2}$ for 7 and $14 \mathrm{~d}$.

As detected by immunohistochemistry, faint diffuse nitrotyrosine immunoreactivity was present in lungs of air-exposed pups with (Fig. 4B) or without SB265610 treatment (Fig. 4A). However, lungs of rats exposed to $60 \% \mathrm{O}_{2}$ showed widespread and more intense immunostaining for nitrotyrosine (Fig. 4C), which was largely prevented by SB265610 treatment (Fig. 4D).

\section{DISCUSSION}

Mounting evidence links maladaptive inflammation to abnormal postnatal lung development. Earlier studies showed

$$
\text { A }
$$

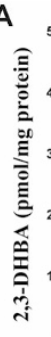

A

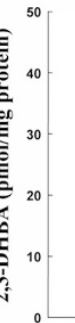

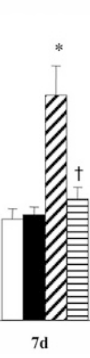

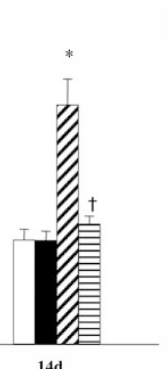

$14 \mathrm{~d}$

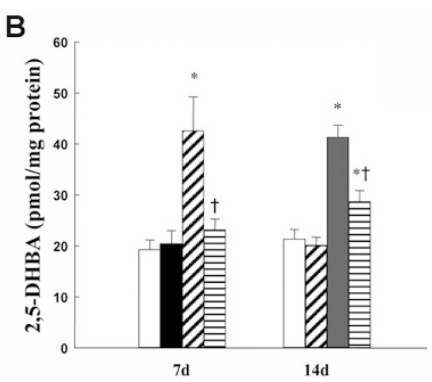

Figure 2. Hydroxyl radical detection in lungs of neonatal rats exposed to air or $60 \% \mathrm{O}_{2}+\mathrm{SB} 265610$ or vehicle on days 7 and 14 (A. 2,3-DHBA; B. 2,5-DHBA). Bars represent mean $\pm \mathrm{SEM}, n=5$. $* p<0.01$, by one-way analysis of variance, for animals exposed to $60 \% \mathrm{O}_{2}$ compared with those in air in the same treatment group. ${ }^{\dagger} p<0.01$, by one-way analysis of variance, for SB265610-treated animals compared with control animals exposed to the

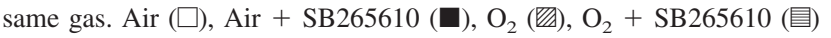

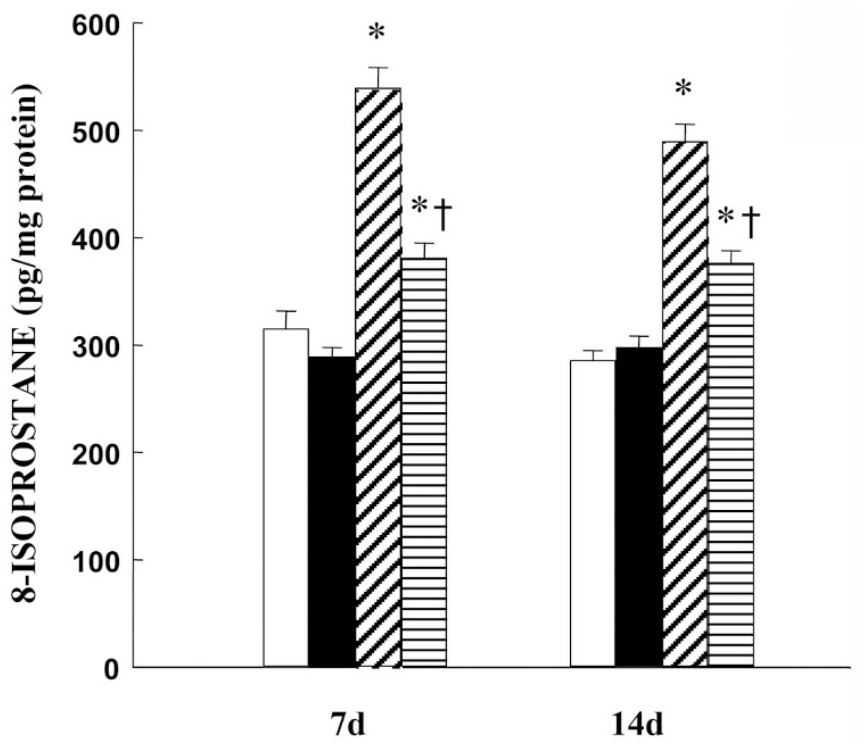

Figure 3. Total 8-isoprostane concentrations in lungs from neonatal rats exposed to air or $60 \% \mathrm{O}_{2}+\mathrm{SB} 265610$ or vehicle for 7 and $14 \mathrm{~d}$. Bars represent mean \pm SEM, $n=5 . * p<0.01$, by one-way analysis of variance, for animals exposed to $60 \% \mathrm{O}_{2}$ compared with those in air in the same treatment group. ${ }^{\dagger} p<0.05$, by one-way analysis of variance, for SB265610treated animals compared with control animals exposed to the same gas. Air

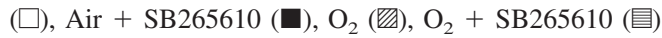

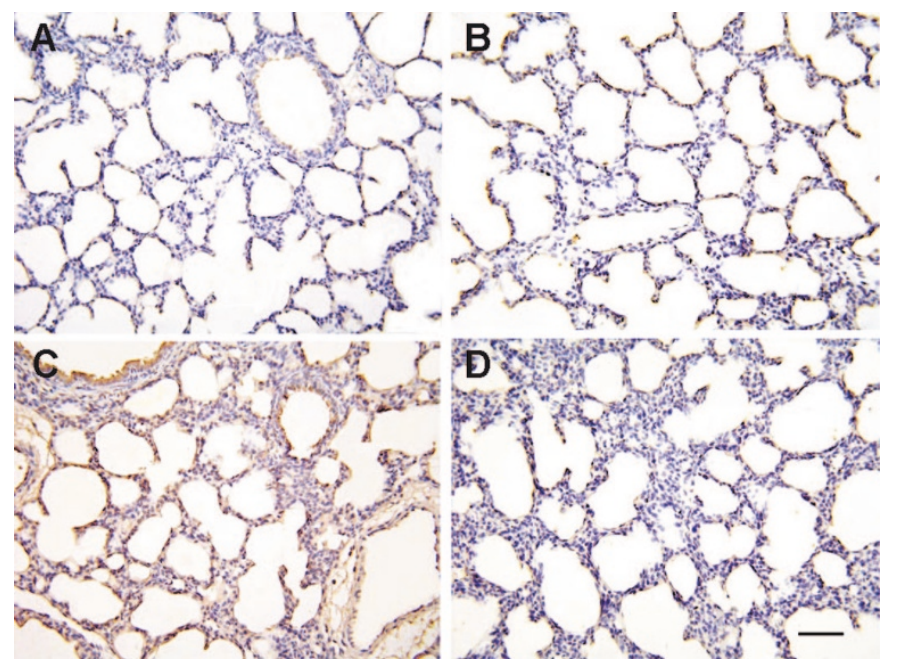

Figure 4. Detection of nitrated protein by nitrotyrosine immunostaining (brown). Neonatal rat pups were exposed to air or $60 \% \mathrm{O}_{2}$ for $7 \mathrm{~d}$ plus SB265610 or vehicle. Faint positive staining was evident in air-exposed newborn rats that had received vehicle $(A)$ or SB265610 $(B)$. Positive staining for nitrotyrosine was more intense and present diffusely in the lungs of $60 \%$ $\mathrm{O}_{2}$-exposed newborn rats that had received vehicle $(C)$. Newborn rats treated with $60 \% \mathrm{O}_{2}$ and SB265610 had a similar intensity of staining to air control animals $(D)$. Bar length $=50 \mu \mathrm{m}$.

that blocking neutrophil influx could partly protect alveolar development $(7,9)$. Because our earlier studies showed that DNA oxidation and superoxide accumulation were reduced following neutrophil blockade, we wanted to determine whether other molecular targets were also protected by this strategy.

We found that blocking neutrophil influx largely prevented pulmonary hydroxyl radical accumulation. There is also evidence (14) that hydroxyl radicals are the most important free 
radicals responsible for the growth-inhibiting effects of hyperoxia on mouse fetal lung morphogenesis. The best recognized mechanism of hydroxyl radial formation (15) is by the Fenton reaction, in which divalent redox ions, such as iron, serve as catalysts. Romas and colleagues (16) reported a myeloperoxidase-dependent mechanism of hydroxyl radical generation which does not require a supplemental iron catalyst, that is, myeloperoxidase-generated hypohalous acid ( $\mathrm{HOCl}$ or $\mathrm{HOBr}$ ) reacting with intracellular superoxide to form the hydroxyl radical.

Hyperoxia may lead to free radical-mediated lipid peroxidation, and then result in the destruction of cell membrane and tissue injury (17). In this study, we used 8-isoprostane to monitor lipid peroxidation levels. 8-isoprostane has been widely used to quantify oxidative stress in various conditions (18). Moreover, it also exerts a number of biologic activities in the lung, including smooth muscle contraction and proliferation and fibroblast chemotaxis and proliferation (19). A recent study (20) reported that plasma 8-isoprostane concentrations in infants destined to develop BPD were significantly higher at 3 and $7 \mathrm{~d}$ of life than in those not developing BPD, suggesting that plasma 8-isoprostane could serve as a marker for assessing the risk for BPD development in pre-term infants. Our results suggest that activated neutrophils play a role in the process of lipid peroxidation in the lungs of newborn rats during exposure to hyperoxia. This conclusion is supported by evidence (21) that myeloperoxidase is secreted by activated neutrophils and may serve as an alternative enzymatic participant in the initiation of lipid peroxidation in vivo.

Our study suggested that neutrophils may also play a role in the formation of nitrotyrosine, a marker of reactive nitrogen species generation. A recent report noted that activated neutrophil heme-protein peroxidase activity, in particular neutrophil-derived myeloperoxidase (22), significantly contributes to nitrotyrosine formation in vivo. These results were consistent with those findings in hyperoxia-exposed adult rats, Baldus and colleagues (23) reported that myeloperoxidase immunoreactivity strongly colocalized with nitrotyrosine formation in hyperoxia-exposed adult rats, both of the signals being distributed in subendothelial and epithelial regions. Nitrotyrosine is produced by the reaction of reactive nitrogen species with proteins containing tyrosine residues. Several studies have focused on identifying target nitrated proteins, and Mn-SOD (24), tyrosine phosphatases (25), cytochrome P450 (26), ribonucleotide reductase (27) and extracellular matrix protein fibronectin (28) have been found to be nitrated. It is believed that some nitrated proteins are inactivated and dysfunctional. However, as tyrosine groups are also the target of phosphorylase, protein nitration may be an important mechanism for posttranslational protein modification (25).

Our data on protein content in BAL and WW/DW indicated that blocking neutrophil influx partly relieved hyperoxiamediated lung edema. A recent study reported that CXCR2 knock-out adult mice had almost no signs of hyperoxiainduced lung injuries (29). Our model used a significantly lower $\mathrm{FiO}_{2}$, since it was aimed at producing impaired lung development that mimics BPD, rather than acute lung injury. Our expected and observed degree of protein leak was less than typically observed in hyperoxia-induced injury in adult rodents $(6,30)$.

There is a growing body of evidence that free radicals are required for normal cellular metabolism, proliferation, and differentiation (12,31-33). Antagonism of CXCR2 using SB265610 does not appear to affect basal ROS accumulation, since there were no differences between vehicle and SB265610 treated air-exposed groups, and since our previous report showed no adverse effects on lung development (9).

Expression of CXCR2 has been demonstrated in many other cell types, including non-hematopoietic cells such as endothelial cells. Although these cells could also be affected by the inhibitor, contributing to the observed protection, we found no effects, except in the hyperoxia-exposed group. It could be that antagonizing CXCR2 might affect eosinophils, monocytes (34), or mast cell targeting (35), but we did not examine this directly. CXCR2 function in pulmonary vascular endothelial cells and in bronchiolar epithelium is only now being explored, and may be required for full expression of pulmonary inflammation (36). Effects of SB265610 in these other cells types could have contributed to the observed lung protection, but would have done so predominantly via their indirect effects on neutrophil accumulation.

The present study demonstrates that neutrophils are the significant intermediate sources of hydroxyl radical that accumulates in hyperoxia-exposed newborn rat lung, and that blocking neutrophil influx can substantially reduce important downstream products of reactions with hydroxyl radicals, such as 8-isoprostane. Together with our previous studies, our present findings show that blocking neutrophil influx protects alveolar development and improves lung function, in part by preventing hydroxyl radical accumulation and lipid peroxidation.

Acknowledgments. This study was supported by the National Natural Science Foundation of China (NSFC) (No.30271379, XL), NSFC National Science Fund for Distinguished Young Investigator (No.30125019, XL; No.30225040, QN), and National Basic Research Program (973 Project 2005CB522507, XL), and National Institutes of Health HL-067021 (RLA). Dr. Tanswell holds the Hospital for Sick Children Women's Auxiliary Chair in Neonatal Medicine.

\section{REFERENCES}

1. Speer CP 2003 Inflammation and bronchopulmonary dysplasia. Semin Neonatol 8:29-38

2. Van Marter LJ, Dammann O, Allred EN, Leviton A, Pagano M, Moore M, Martin C Developmental Epidemiology Network Investigators 2002 Chorioamnionitis, mechanical ventilation, and postnatal sepsis as modulators of chronic lung disease in preterm infants. J Pediatr 140:171-176

3. Kotecha S, Chan B, Azam N, Silverman M, Shaw RJ 1995 Increase in interleukin-8 and soluble intercellular adhesion molecule-1 in bronchoalveolar lavage fluid from premature infants who develop chronic lung disease. Arch Dis Child Fetal Neonatal Ed 72:F90-F96

4. Coalson JJ, Winter VT, Siler-Khodr T, Yoder BA 1999 Neonatal chronic lung disease in extremely immature baboons. Am J Respir Crit Care Med 160:1333-1346

5. Carlton DP, Albertine KH, Cho SC, Lont M, Bland RD 1997 Role of neutrophils in lung vascular injury and edema after premature birth in lambs. J Appl Physiol $83: 1307-1317$

6. Deng H, Mason SN, Auten RL 2000 Lung inflammation in hyperoxia can be prevented by antichemokine treatment in newborn rats. Am J Respir Crit Care Med $162: 2316-2323$ 
7. Auten RL, Mason SN, Tanaka DT, Welty-Wolf K, Whorton MH 2001 Antineutrophil chemokine preserves alveolar development in hyperoxia-exposed newborn rats. Am J Physiol Lung Cell Mol Physiol 281:L336-L344

8. Auten RL, Whorton MH, Mason SN 2002 Blocking neutrophil influx reduces DNA damage in hyperoxia-exposed newborn rat lung. Am J Respir Cell Mol Biol 26:391-397

9. Yi M, Jankov RP, Belcastro R, Humes D, Copland I, Shek S, Sweezey NB, Post M, Albertine KH, Auten RL, Tanswell AK 2004 Opposing effects of $60 \%$ oxygen and neutrophil influx on alveologenesis in the neonatal rat. Am J Respir Crit Care Med 170:1188-1196

10. Han RN, Buch S, Tseu I, Young J, Christie NA, Frndova H, Lye SJ, Post M, Tanswell AK 1996 Changes in structure, mechanics, and insulin-like growth factorrelated gene expression in the lungs of newborn rats exposed to air or $60 \%$ oxygen. Pediatr Res 39:921-929

11. Bradford MM 1976 A rapid and sensitive method for the quantitation of microgram quantities of protein utilizing the principle of protein-dye binding. Anal Biochem 72:248-254

12. Luo X, Christie NA, McLaughlin MA, Belcastro R, Sedlackova L, Cabacungan J, Freeman BA, Tanswell AK $1999 \mathrm{H}_{2} \mathrm{O}_{2}$ mediates $\mathrm{O}_{2}$ toxicity in cultured fetal rat distal lung epithelial cells. Free Radic Biol Med 26:1357-1368

13. Luo X, Sedlackova L, Belcastro R, Cabacungan J, Lye SJ, Tanswell AK 1999 Effect of the 21-aminosteroid U74389G on oxygen-induced free radical production, lipid peroxidation, and inhibition of lung growth in neonatal rats. Pediatr Res 46:215-223

14. Wilborn AM, Evers LB, Canada AT 1996 Oxygen toxicity to the developing lung of the mouse: role of reactive oxygen species. Pediatr Res 40:225-232

15. Motohashi N, Mori I 1983 Superoxide-dependent formation of hydroxyl radical catalyzed by transferrin. FEBS Lett 157:197-199

16. Ramos CL, Pou S, Rosen GM 1995 Effect of anti-inflammatory drugs on myeloperoxidase-dependent hydroxyl radical generation by human neutrophil. Biochem Pharmacol 49:1079-1084

17. Roberts RJ, Rendak I, Bucher JR 1983 Lipid peroxidation in the newborn rat: influence of fasting and hyperoxia on ethane and pentane in expired air. Dev Pharmacol Ther 6:170-178

18. Montuschi P, Collins JV, Ciabattoni G, Lazzeri N, Corradi M, Kharitonov SA, Barnes PJ 2000 Exhaled 8-isoprostane as an in vivo biomarker of lung oxidative stress in patients with COPD and healthy smokers. Am J Respir Crit Care Med 162:1175-1177

19. Janssen LJ 2001 Isoprostanes: an overview and putative roles in pulmonary pathophysiology. Am J Physiol Lung Cell Mol Physiol 280:L1067-L1082

20. Ahola T, Fellman V, Kjellmer I, Raivio KO, Lapatto R 2004 Plasma 8-isoprostane is increased in preterm infants who develop bronchopulmonary dysplasia or periventricular leukomalacia. Pediatr Res 56:88-93

21. Zhang R, Brennan ML, Shen Z, MacPherson JC, Schmitt D, Molenda CE, Hazen SL 2002 Myeloperoxidase functions as a major enzymatic catalyst for initiation of lipid peroxidation at sites of inflammation. J Biol Chem 277:46116-46122

22. van der Vliet A, Eiserich JP, Halliwell B, Cross CE 1997 Formation of reactive nitrogen species during peroxidase-catalyzed oxidation of nitrite. A potential additional mechanism of nitric oxide-dependent toxicity. J Biol Chem 272:76177625

23. Baldus S, Eiserich JP, Brennan ML, Jackson RM, Alexander CB, Freeman BA 2002 Spatial mapping of pulmonary and vascular nitrotyrosine reveals the pivotal role of myeloperoxidase as a catalyst for tyrosine nitration in inflammatory diseases. Free Radic Biol Med 33:1010-1019

24. Mamo LB, Suliman HB, Giles BL, Auten RL, Piantadosi CA, Nozik-Grayck E 2004 Discordant extracellular superoxide dismutase expression and activity in neonatal hyperoxic lung. Am J Respir Crit Care Med 170:313-318

25. Klotz LO, Schroeder P, Sies H 2002 Peroxynitrite signaling: receptor tyrosine kinases and activation of stress-responsive pathways. Free Radic Biol Med 33:737743

26. Janig GR, Makower A, Rabe H, Friedrich J, Ruckpaul K 1984 Chemical modification of tyrosine residues at the active centre of cytochrome P-450 CAM. Biomed Biochim Acta 43:K17-K24

27. Guittet O, Decottignies P, Serani L, Henry Y, Le Marechal P, Laprevote O, Lepoivre M 2000 Peroxynitrite-mediated nitration of the stable free radical tyrosine residue of the ribonucleotide reductase small subunit. Biochemistry 39:4640-4648

28. Baldus S, Eiserich JP, Mani A, Castro L, Figueroa M, Chumley P, Ma W, Tousson A, White CR, Bullard DC, Brennan ML, Lusis AJ, Moore KP, Freeman BA 2001 Endothelial transcytosis of myeloperoxidase confers specificity to vascular ECM proteins as targets of tyrosine nitration. J Clin Invest 108:1759-1770

29. Sue RD, Belperio JA, Burdick MD, Murray LA, Xue YY, Dy MC, Kwon JJ, Keane MP, Strieter RM 2004 CXCR2 is critical to hyperoxia-induced lung injury. J Immunol 172:3860-3868

30. Gerik SM, Keeney SE, Dallas DV, Palkowetz KH, Schmalstieg FC 2003 Neutrophi adhesion molecule expression in the developing neonatal rat exposed to hyperoxia. Am J Respir Cell Mol Biol 29:506-512

31. Jankov RP, Negus A, Tanswell AK 2001 Antioxidants as therapy in the newborn: some words of caution. Pediatr Res 50:681-687

32. Jankov RP, Luo X, Cabacungan J, Belcastro R, Frndova H, Lye SJ, Tanswell AK 2000 Endothelin-1 and $\mathrm{O}_{2}$-mediated pulmonary hypertension in neonatal rats: a role for products of lipid peroxidation. Pediatr Res 48:289-298

33. Li N, Oberley TD 1998 Modulation of antioxidant enzymes, reactive oxygen species, and glutathione levels in manganese superoxide dismutase-overexpressing NIH/3T3 fibroblasts during the cell cycle. J Cell Physiol 177:148-160

34. Barnes PJ 2003 Cytokine-directed therapies for the treatment of chronic airway diseases. Cytokine Growth Factor Rev 14:511-522

35. Abonia JP, Austen KF, Rollins BJ, Joshi SK, Flavell RA, Kuziel WA, Koni PA, Gurish MF 2005 Constitutive homing of mast cell progenitors to the intestine depends on autologous expression of the chemokine receptor CXCR2. Blood 105:4308-4313

36. Reutershan J, Morris MA, Burcin TL, Smith DF, Chang D, Saprito MS, Ley K 2006 Critical role of endothelial CXCR2 in LPS-induced neutrophil migration into the lung. J Clin Invest 116:695-702 